\title{
Monitoring the vegetation structure of south-central Etosha National Park using terrestrial photographs
}

\author{
M.H.T. Hipondoka and W.D. Versfeld
}

Hipondoka, M.H.T. and W.D. Versfeld. 2003. Monitoring the vegetation structure of south-central Etosha National Park using terrestrial photographs. Koedoe 46(1): 17-27. Pretoria. ISSN 0075-6458.

In 1984, a ground-based, photographic library was initiated for monitoring the vegetation dynamics in Etosha National Park. Over 400 photographic points were selected. At these points, panchromatic photographs were taken at intervals of six years. This study was undertaken to assess the applicability of this terrestrial photographic library in characterising the dynamics of the vegetation structure in south-central Etosha National Park. The methods employed include field validation, visual photograph interpretations, spatial analysis, and aggregated two-dimensional tables. Results, though patchy in nature, show that the vegetation structure at $63 \%$ of the sites covered remained either unchanged or increased over the 15 -year study period. The patchiness of the photo points can be exploited and be treated as training sites for corresponding satellite image classifications to provide continuous ground coverage results.

Key words: Etosha, photographs, savanna, vegetation.

M.H.T. Hipondoka and W. D. Versfeld $\varangle$, Etosha Ecological Institute, PO Box 6, OkaukuejoviaOutjo, Namibia (mhipondoka@yahoo.com / eei.staff@mweb.com.na).

\section{Introduction}

Management of a national park of Etosha's size $\left(22270 \mathrm{~km}^{2}\right)$ often presents challenges. Constant and up-to-date scientific feedback is essential to enable timely and adaptive management practices. Before the relatively recent widespread application of satellite remote sensing technologies that can be used to survey and monitor the environment, Etosha National Park (Etosha NP), due to its size, was confronted with the challenge of adopting a reliable and consistent method of monitoring its vegetation dynamics. Consequently, a terrestrial photo-point system was initiated in 1984 (Etosha Ecological Institute 1984).

The terrestrial photo-point system forms a visual record of short, medium and long-term changes taking place in the vegetation properties (Joubert 1983). Graetz \& Pech (1987), however, heavily criticised this method when they tested it for land cover changes in remote arid lands of Australia. They concluded that it did not afford any possibility to accurately estimate the dynamics of land cover. Yet, these authors acknowledged its potential for collecting records of re-vegetation at established permanent sites.

Generally, in spatial analyses vertical aerial photographs are preferred to oblique photographs, particularly, in terms of geometric fidelity (Lillesand \& Kiefer 1994; Campbell 1996). Oblique photographs, however, offer the advantage of a more natural view-angle, and the ability to view objects that occur under the canopy (Campbell 1996; Fahsi 2001). Of equal importance, is the fact that because oblique aerial photos are not used for photogrammetric and precision purposes, given their poor geometric fidelity, they may use inexpensive cameras. The terrestrial photo point system was therefore deemed as a cost effective and easily applicable method that would meet the demand for vegetation data collection of Etosha NP. This paper presents the results of applying and assessing this method as a ground-based system for 
monitoring the vegetation dynamics of Etosha National Park.

\section{Methods}

In this paper, the term 'photo point' is used to describe specific plots where photographs were taken. At each photo point, sets of four photographs were usually taken to capture the northern, southern, eastern and western view of the plot. The term 'site' is used to refer to these four views of the photo point. Analysis was carried out at the site level, as the vegetation structure of the same plot was not necessarily always homogeneous.

\section{Study Area}

Etosha National Park is located in northern Namibia and comprises a surface area of $22270 \mathrm{~km}^{2}$ (Lindaque \& Archibald 1991). Etosha Pan, a saline depression covering a total of $4500 \mathrm{~km}^{2}$ or $20 \%$ of the park, is a prominent feature of the area. Fourteen (14) vegetation structure classes are recognised in Etosha NP, ranging from high tree savanna to grassland (Sannier et al. in prep.).
The park receives summer rainfall and decreases along an East-West gradient, the East being wetter (Engert 1997). Figure 1 presents the annual rainfall received between 1980 and 1999 at Okaukuejo and Ombika, both located within the study area. Although the two stations are only $17 \mathrm{~km}$ apart, comparatively, Ombika receives higher rainfall than Okaukuejo. The long-term average annual rainfall at Okaukuejo and Ombika is $320 \mathrm{~mm}$ and $382 \mathrm{~mm}$, respectively. Essentially, the study area is characterised by erratic rainfall, both in space and time (Engert 1997).

As a test phase, this study was limited to the southcentral part of Etosha NP (Fig. 2), covering a surface area of $1936 \mathrm{~km}^{2}$. All vegetation structure classes, but 'high tree savanna high', occur in the study area.

The area extends from the park's southern boundary to Adamax Pan in the North, and from Kapupuhedi waterhole in the East to Grunewald waterhole in the West. The study area is covered by a total of 60 photo points, generating approximately 230 photographs each survey year.

\section{Data Acquisition}

Due to the risk of being unable to re-identify the photo points in subsequent visits, and the absence of

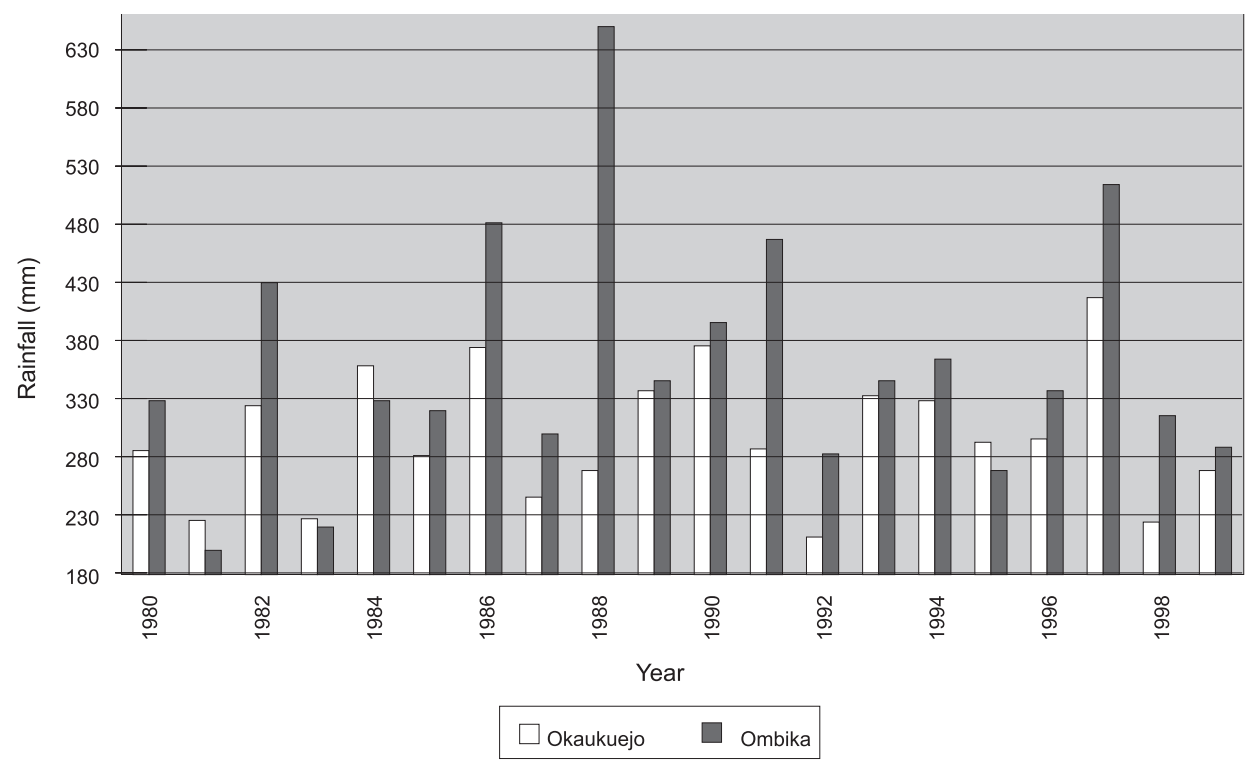

Fig. 1. Annual rainfall received at Okaukuejo and Ombika between 1980 and 1999. 


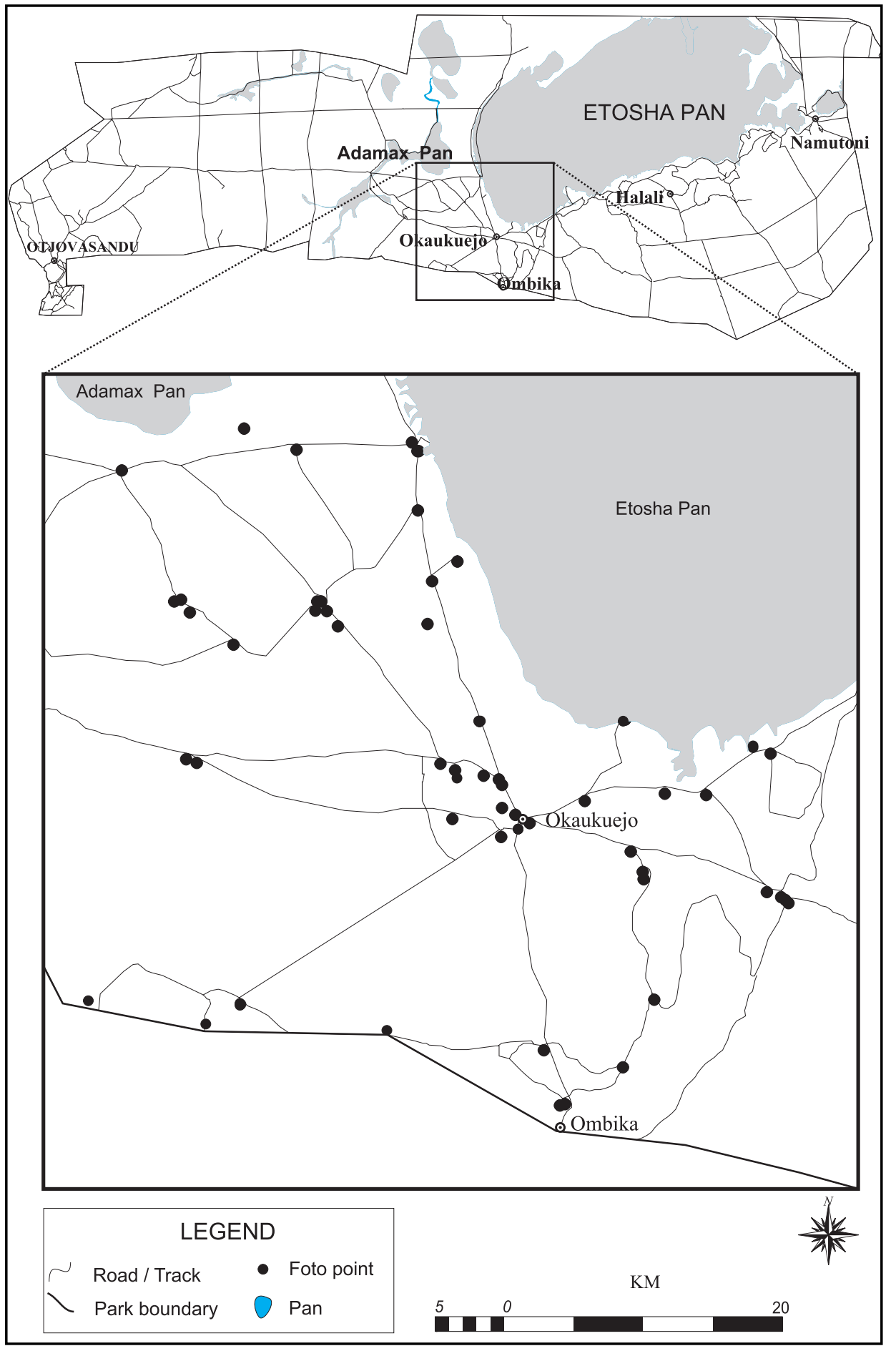

Fig. 2. Location of the study area and photo points in Etosha National Park 
Global Positioning System (GPS) technologies at the time, photographic points were out of necessity subjectively selected. Monitoring sites were therefore located near places or structures such as roads or track junctions, waterholes, gravel pits, road-signs, horse camps, along pan margins and the park's boundary fence (Etosha Ecological Institute 1984). However, these sites were not necessarily representative of the rangeland, given their proximity to both anthropogenic impact and higher game concentrations. Milton et al. (1998), for example, suggest that rangeland monitoring sites should be located at least $20 \mathrm{~m}$ from a track or fence and $100 \mathrm{~m}$ from watering points. The goal, however, was to detect change in the vegetation and in taking into consideration the fact that both man and beast are the primary landusers of the park, the justification of establishing the photo points at these localities was warranted.

Photographs were first taken in 1984 and repeated in 1990 and 1996. A total of 442 photo points are currently in use, including a fraction of photo points that could not be re-identified in successive visits and new ones that were subsequently created to replace them in the same localities. The photo points are spread across the park and cover all the vegetation types. The major pans, such as Etosha and Adamax, were however not covered.

A $35 \mathrm{~mm}$ single lens reflex FM Nikon camera body with a standard $50 \mathrm{~mm}$ lens and a panchromatic 100ASA film was used consistently. At each site, photographs were taken from a vehicle's rooftop, a windmill or road sign-block platform. Photographs were taken towards each of the four cardinal compass bearings (i.e. North, East, South and West) to ensure a panoramic, representative and holistic view of the entire plot. Consistency was maintained for capturing $7 / 8$ th of the subject matter covering the land surface, and the remainder ( $1 / 8$ th) contained the horizon. Photographs were taken during the dry, winter months of July and August, when tree leaves are off. Although photographs taken when trees have their leaves out have an advantage of tree species identification (Lathrop 1999), the timing of these photographs was primarily dictated by accessibility to all parts of the park (not possible during the rainy season) and to coincide with the season that the national aerial photograph series are taken. An oversight, however, was that successive photographs of the same plot were not taken at the same time of day, given that the routes taken and time of exposure were not recorded. Photographs were processed locally, using standard processing procedures.

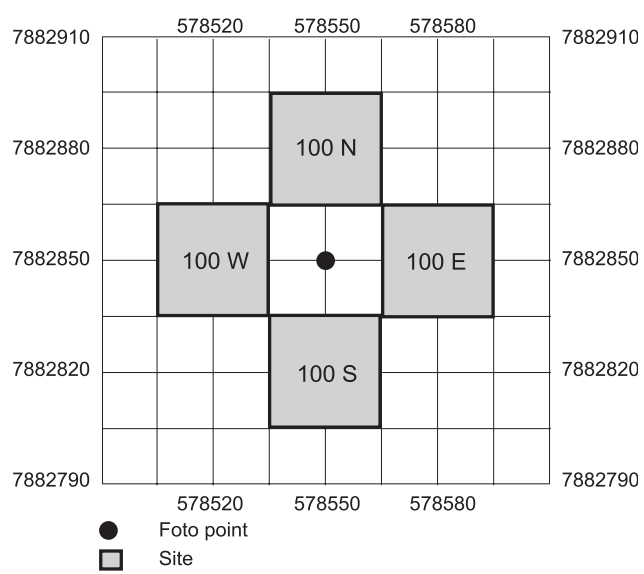

Fig. 3. Geo-coding of sites as derived from the original coordinates of the photo point.

\section{Data Processing and Analysis}

Before the analysis and interpretation of the photographs commenced, field verification was conducted in 1999, during the dry season. Essentially, this exercise entailed familiarization of the interpreter with the sites to be interpreted (Estes 2001). The sites were located with the help of a GPS (Garmin 45XL) and the photographs of 1996. At each site, a classification of the vegetation structure was made, based on Bougey's (1957, cited by Sannier et al. 1995) classification scheme, which was adapted to the semi-arid conditions of Etosha by Sannier et al. (1995). Two vegetation attributes, height and crown cover, were used to determine the vegetation structure of each site. The decision tree used for the structural vegetation description was adapted from Du Plessis (1999), in which the model and details are provided. Briefly, this method defines the vegetation structures based upon combinations of plant height and canopy cover. Examples of height descriptions are: high tree savanna, low tree savanna, shrub savanna, grass savanna, steppe and grassland; whilst the canopy cover was categorised in qualitative terms, e.g. low, medium and high. Thus, the vegetation type 'steppe' could be, for example, subdivided into 'steppe very low', 'steppe low' and 'steppe medium'. Exceptions in the classes used, were for sites that were devoid of vegetation, due to human activities, such as gravel pits, which were classified accordingly. The results of field verification were summarised as the structural vegetation classification of 1999. 
Subsequently, each photograph taken in each of the three study year's, 1984, 1990 and 1996, was interpreted using the above classification. To maximise consistency, the same author carried out all visual photo interpretations. The other author crosschecked a $30 \%$ sample, randomly selected from the interpretation results. This crosschecking resulted in a high degree $(91 \%)$ of agreement. The interpretation results were recorded in a spreadsheet.

To facilitate spatial analysis of the interpretation results under a Geographic Information System (GIS), sites were geo-coded using Universal Transverse Mercator (UTM) coordinates. The UTM grid system was favoured for its measuring units (meters), which simplified the process of geo-coding sites. Moreover, a map grid is more appropriate than geographical coordinates for large-scale maps (Sannier et al. 2002). To avoid sites of the same plot overlapping in a map format, the appropriate UTM coordinate values of each photo point were offset by a $30 \mathrm{~m}$ distance towards the respective direction of each plot view. For example, the easting and northing of photo point 100 , presented in Fig. 3, is 578550 and 7882850 , respectively. The coordinates of site $100 \mathrm{~N}$ (north) were obtained by adding 30 to 7882850 (northing value), while the easting figure remains unchanged. The coordinates for the centre point of site $100 \mathrm{~N}$ would therefore read 578550 and 7882880 for the easting and northing, respectively. The same technique was then used to derive the coordinates for the sites in the South, East and West.

Integrated Land and Water Information System (ILWIS) software (ITC, Enschede, The Netherlands) was used for spatial analysis. The interpretation results were imported into ILWIS in a table format and subsequently converted to point maps, in both vector and raster format. Raster maps were resampled to a $30 \mathrm{~m}$ pixel size. Data query, retrieval and display were done in both map and table formats. These included identifying sites where the vegetation structure remained consistently unchanged during the study period, using the equation:

Mapout $:=i f f(($ map84 $=$ map90 $)$ and $($ map84 $=$ map96 $)$ and $($ map $84=$ map 99$)$ and $($ map $90=$ map 96$)$ and $($ map 90 =map99)and (map96=map99)), map84,"?")

... (Equation 1)

Where mapout is the name of the output map, map84, map90 and map96 is the vegetation structure classes of 1984, 1990 and 1996, in that order, and map99 is the field validation results.

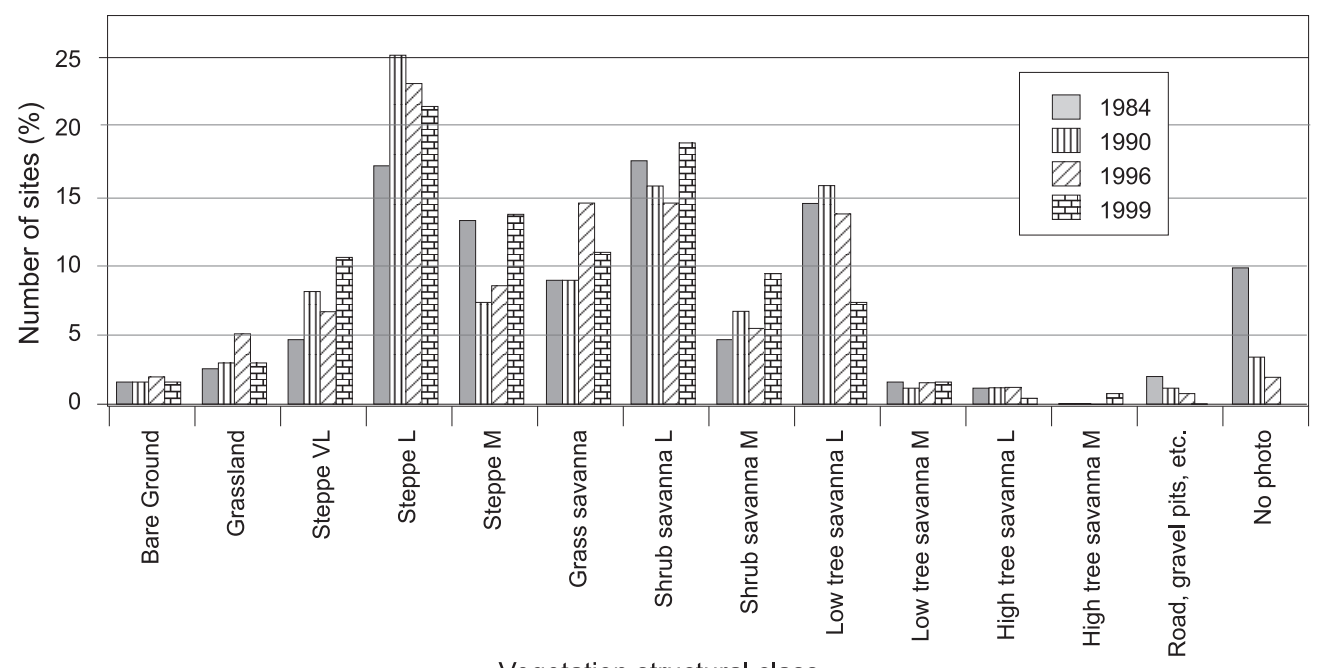

Vegetation structural class

Fig. 4. Distributions and fluctuation patterns of the vegetation structure during the survey years. (Note: photo points that could not be re-identified in subsequent visits and new ones created to replace them are grouped under "no photo" in the figure.) 
In order to capture the conversion of the vegetation structure classes between any two study years, the "map crossing" function was applied. The results, in table format, were transformed into matrixes.

\section{Results}

Figure 4 depicts the recorded distributions and fluctuation patterns of the vegetation structure for all survey years. During the study years, 'steppe low' was the dominant vegetation structure, followed by 'shrub savanna low'. Few sites were classified as 'bare ground', while a fraction of others, were characterised by man-made features, such as gravel pits, tracks and roads. Fluctuations among survey years were largest for 'low tree savanna low' (Coefficient of variation $(\mathrm{CV})=59.6 \%)$, 'steppe low' $(\mathrm{CV}=48.69$ $\%)$ and 'steppe medium' (CV=43.5\%) and lowest for 'bare ground' $(\mathrm{CV}=0.2 \%)$, low tree savanna medium' (CV=0.2\%), 'high tree savanna low' $(\mathrm{CV}=0.8)$ and 'high tree savanna medium' $(\mathrm{CV}=0.8)$.

Using the vegetation structural classes of 1984 as the baseline condition, variations in vegetation structural classes between 1984 and subsequent survey years were obtained (Fig. 5). In 1990, the vegetation structure types at $64 \%$ of the sites remained unchanged, whereas $23 \%$ declined and $13 \%$ increased from the previous classification of 1984. The number of sites, where the vegetation structure remained unchanged when compared with the baseline data, decreased by $10 \%$ in 1996 , to $54 \%$. In contrast, the number of sites with increased and declined vegetation structure raised to $17 \%$ and $29 \%$, respectively, in 1996.

The variations between the field results and the baseline show that sites with the same classification and those that declined in their vegetation structure between the two dates, tied at $37.3 \%$, whilst $25.4 \%$ of the sites experienced growth. Over the entire study period, the number of sites that remained unchanged declined steadily, whilst a steady increase occurred in sites with a decline and incline of the vegetation structure.

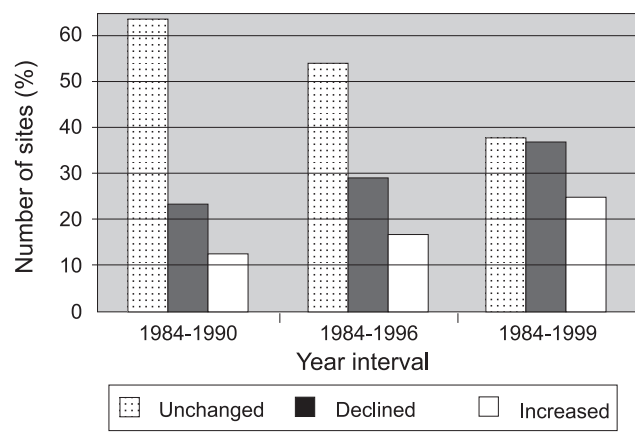

Fig. 5. Overall changes of the vegetation structure compared with the baseline condition.

The preceded changes identified after 1990, do not make a distinction between sites with change in the vegetation structure between one or two survey years, but returned to the baseline condition in later survey years and those that remained consistently unchanged and progressively declined or increased. For example, site $200-\mathrm{N}$, classified as 'steppe very low' in 1984, was categorised as 'steppe low' in 1990 and in 1996 its vegetation was recorded to have returned to the baseline condition. It was thus accounted for having its vegetation structure declined in

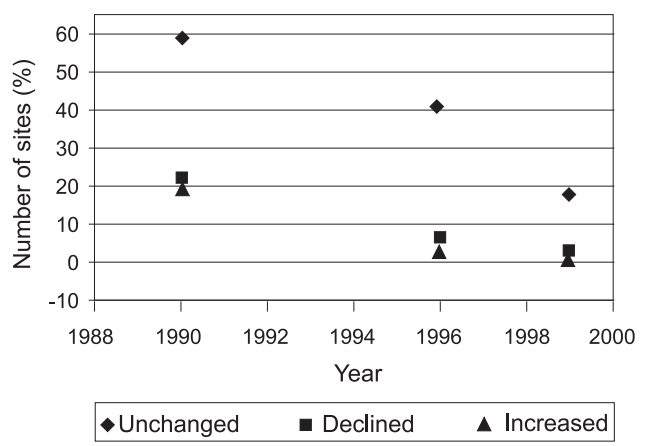

Fig. 6. Trend of sites with consistently unchanged, and progressively declined or increased vegetation structural classes. 
4 = number of sites with vegetation structure unchanged

4 = number of sites with vegetation structure increased
4 $=$ number of sites with vegetation structure declined $=$ new sites after 1984 .

\begin{tabular}{|c|c|c|c|c|c|c|c|c|c|c|c|c|c|c|}
\hline 1999 & 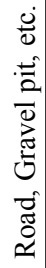 & 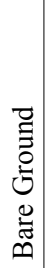 & 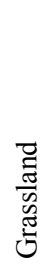 & 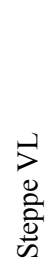 & $\mid \begin{array}{c}1 \\
\tilde{D} \\
\frac{2}{2} \\
\stackrel{\tilde{D}}{\omega}\end{array}$ & $\begin{array}{l}\Sigma \\
0 \\
\frac{a}{2} \\
\stackrel{\Delta}{\infty}\end{array}$ & 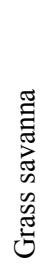 & 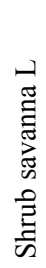 & 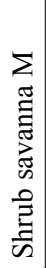 & 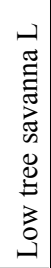 & 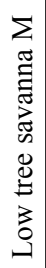 & 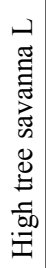 & 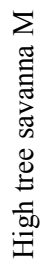 & 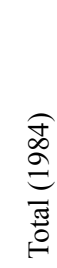 \\
\hline No photo & & & & & 10 & 4 & 6 & 1 & & 2 & & & & 23 \\
\hline Road/Gravel pit, etc. & & & & & & & & 4 & & & 1 & & & 5 \\
\hline Bare Ground & & 4 & & & & & & & & & & & & 4 \\
\hline Grassland & & & 2 & & 3 & & & 1 & & & & & & 6 \\
\hline Steppe very low & & & 1 & 4 & 5 & & 1 & & & & & & & 11 \\
\hline Steppe low & & & & 13 & 18 & 9 & & & & & & & & 40 \\
\hline Steppe medium & & & & 6 & 9 & 16 & & & & & & & & 31 \\
\hline Grass savanna & & & & 1 & 2 & 3 & 5 & 7 & 3 & & & & & 21 \\
\hline Shrub savanna low & & & 1 & 1 & 1 & & 8 & 17 & 11 & 2 & & & & 41 \\
\hline Shrub savanna medium & & & & & 2 & & 1 & 5 & 2 & 1 & & & & 11 \\
\hline Low tree savanna low & & & 3 & & & & 4 & 8 & 6 & 10 & 3 & & & 34 \\
\hline Low tree savanna medium & & & & & & & 1 & 1 & & 2 & & & & 4 \\
\hline High tree savanna low & & & & & & & & & & & & 1 & 2 & 3 \\
\hline High tree savanna medium & & & & & & & & & & & & & & 0 \\
\hline Total (1999) & 0 & 4 & 7 & 25 & 50 & 32 & 26 & 44 & 22 & 17 & 4 & 1 & 2 & 234 \\
\hline
\end{tabular}

1990 and remained unchanged under the 1996 classification.

Tracking of these dynamics show a distinct trend in the structural vegetation classes of sites that consistently remained unchanged, progressively declined or increased over the entire study period. This trend is captured in Fig. 6, where a negative linear relationship with time appears to emerge, although more data is needed for that purpose.

By 1999 , only one site, located some $2.5 \mathrm{~km}$ north of Ombika waterhole, where the vegetation structure increased progressively. In contrast, only two sites experienced progressive decline in their vegetation structure during the same period. Both sites are located 
within one kilometre radius from either Leeubron waterhole (closed since 1974) or Okaukuejo waterhole. Moreover, the vegetation structure at 47 or $20 \%$ of the sites remained consistently unchanged over the entire study period. These sites are scattered in all vegetation structure types and at varying distances from areas of high human impact and/or animal concentrations. For example, the status of three sites (two sites with 'steppe low' and one with 'grassland' classification) located within $400 \mathrm{~m}$ radius from Okondeka waterhole, remained unchanged since 1984.

Conversion of the vegetation structure between the survey years is another aspect that was investigated. Table 1 presents the matrix of the vegetation structural class conversion between 1984 and 1999. Of particular interest in this analysis are $25 \%$ of sites where the vegetation structure increased. Among these sites, five of them, originally influenced by human activities i.e. gravel pits, gate or track, in 1984, were classified as either 'shrub savanna low' or 'low tree savanna medium' in 1999. Acacia newbrownii, a renowned natural invasive tree species, dominates one of the sites located in the periphery of a gravel pit, while another site is located along the edge of a tar road. Two other sites, where the vegetation structure increased, are located within $400 \mathrm{~m}$ radius from waterholes (Leeubron or Gemsbokvlakte). One of these sites shifted from 'grassland' to 'shrub savanna low', and the other from 'steppe very low' to 'grass savanna'.

At the other end of the spectrum, there are four sites where the vegetation structure declined from either 'shrub savanna low' (one site) or 'low tree savanna low' (three sites) in 1984 to 'grassland' in 1999. These sites are located some tens of meters from waterholes (Okaukuejo, Ombika or Leeubron). In addition, the structural class at five sites declined to 'steppe low' from 'grass savanna' (two sites), 'shrub savanna low' (one site) or 'shrub savanna medium' (two sites). Of all the sites with declined status in $1999,59.5 \%$ of them were within one class margin relative to their original baseline conditions.

\section{Discussions}

The main objective of this study was to evaluate the potential of terrestrial photographs as an approach for monitoring the vegetation structure through time. Our results obtained from the photo interpretations indicate that they are comparable with the data collected from field validations. Although noticeable differences, such as a low number of sites classified as 'low tree savanna low' in 1999 in relation to the other three years, occurred between the two methods, we do not consider such differences as a consequence of wrongly interpreting the vegetation structure from either the photographs or field validations. Rather, as it will be discussed later, these differences are more likely to be related to the response of the vegetation to the accumulated effect of natural factors, such as rainfall and herbivores.

With a relatively good agreement obtained between field validations and terrestrial photo interpretations, a photo point system of Etosha NP shows a promising role to play in supporting the use of satellite remote sensing data, which, as Trodd \& Dougill (1998) noted, are currently not successful in estimating the vegetation structure in a semiarid environment. This is primarily attributed to the limited dimensionality of reflectance data that causes a weak relationship between spectral reflectance and vegetation structure (Trodd \& Dougill 1998; Dramstad et al. 2002). Moreover, the savanna ecosystems, characterised by spatial heterogeneity introduced through the co-existence of herbaceous and woody plants (Scholes \& Walker 1993), increase this challenge for the use of satellite data, such as Landsat TM, in assessing the dynamics of vegetation structure (Hudak \& Wessman 1998). In spite of these limitations, satellite data have the advantages of high temporal resolution and large area coverage. Therefore, in conjunction with satellite data, particularly those with high spatial resolution, a 
photo-point system has the potential of serving as a relevant long-term ground-based monitoring method for the vegetation dynamics of a semi-arid environment. However, the selection of monitoring sites in Etosha NP requires careful consideration, given the fact that the photo-points were subjectively selected and also that they overrepresent areas of high impact.

\section{Analysis of Vegetation Structure}

The results of this study reveal that the vegetation structure of south-central Etosha NP is continuously changing with time. Over the 15-year study period, only a fifth of the sites did not experience change in their vegetation structure. At the same time, the changes experienced at the rest of the sites are not particularly dramatic. There is no obvious trend betraying any preference of change towards or away from any particular structural vegetation class or a group of classes. This condition confirms the notion that stability is not a major feature of savanna ecosystems, while at the same time changes of great magnitude do not occur (Walker \& Noy-Meir 1982; Kempf \& Busche 2002).

The savanna ecosystems are noted for being constantly changing in their vegetation properties in response to anthropogenic activities and the ecological "driving forces" of rainfall, fire regime and grazing level (Lamprey 1979; Walker \& Noy-Meir 1982; Joubert 1983; Scholes \& Walker 1993; Moleele et al. 2001). Although human activity is taking place in the study area, a number of sites that were characterized by anthropogenic impact, such as gravel pits, was small in 1984 and has subsequently decreased in successive study years. This suggests that direct human interference in the park is minimal. The role of herbivores in the study area is difficult to assess, due to a lack of appropriate historical data on game distributions, density and range utilisations. However, elephants were often observed by the authors causing significant damage to the vegetation, particularly at and around waterholes, such as Okaukuejo.
Rainfall in the study area between 1980 and 1999 was generally below the long-term average annual rainfall, with only six out of 20 years the precipitation exceeded the longterm annual average. However, the rainfall variability of this area is illustrated by the fact that years with rainfall above or below the long-term annual average, do not necessarily coincide between the two stations, Okaukuejo and Ombika, both located within the study area. This has practical implications in relating changes in the vegetation structure to rainfall. This study has revealed that, the changes recorded in the vegetation structure have little resemblance to the rainfall pattern. For example, a low number of sites classified as 'low tree savanna low' in 1999 (Fig. 4), relative to the results of photo interpretations, can be attributed to a very low rainfall received in the two consecutive years, 1998 and 1999 (Fig. 1). The higher number of sites classified as 'shrub savanna medium' in 1999, could therefore be accounted for being converted down from the neighbouring class 'low tree savanna low'. This assumption, however, does not apply to fluctuations that occurred in classes ranging from 'steppe very low' to 'shrub savanna low', which all lack a predictable signature. It is therefore probable that the observed lack of relationship between fluctuations in the vegetation structure between years and rain pattern is a direct consequence of rainfall variability, both in space and time, within the study area. This theory of rainfall variability and its bearing on the vegetation trend needs empirical testing. This will be done using data from a dense network of field rain gauges initiated in Etosha NP in 1984 (Du Plessis 1997; Engert 1997), and will be dealt with elsewhere.

The occurrence of fire in the study area during the period under review was infrequent. The last recorded fire occurred in 1976 in the northern part of the study area and in 1990 (after photographs were already taken) and 1991 , in the southern part. None of these fire effects were apparent in the results. In a study aimed at detecting land cover changes in a forested area using TM imagery, Rogan et al. (2002) observed that although there 
was a relationship between fire scars and the decline of the vegetation, not all wildfires were detected using a five-year temporal resolution images. It is therefore likely that a temporal resolution of this scale contains an intrinsic gap in change detection studies, particularly in areas that are subjected to fire.

\section{Conclusions}

The photo point system provided results comparable to field validations. With such a capability, it has the potential to play a supportive role, alongside satellite data, as a parallel, ground-based monitoring system for monitoring the vegetation structure.

\section{Acknowledgements}

We thank W. du Plessis for his encouragement, insights and field calibration of the interpretation method. N. Knox, Dr V. Myers and J. Lates made invaluable remarks on the first draft. We also thank two anonymous reviewers, who made useful comments, which in turn help improved the manuscript. The Namibian Ministry of Environment and Tourism supported all phases of the project in every form.

\section{References}

CAMpBell, J. B. 1996. Introduction to remote sensing. New York: Guilford Press.

Dramstad, W.E., W.J. FJellstad, G.H. Strand, H.F. Mathiesen, G. Engan \& J.N. Stokland. 2002. Development and implementation of the Norwegian monitoring programme for agricultural landscapes. Journal of Environmental Management 64: 49-63.

Du Plessis, W.P. 1997. Refinements to the burning strategy in the Etosha National Park, Namibia. Koedoe 40: 63-76.

Du PLESSIS, W.P. 1999. Linear regression relationships between NDVI, vegetation and rainfall in Etosha National Park, Namibia. Journal of Arid Environment 42: 235-260.

Etosha Ecological Institute. 1984. Motivation for photo point and rain gauge layout system in Etosha National Park. Okaukuejo. Unpublished internal report (N 18/2/1/30).

ENGERT, S. 1997. Spatial variability and temporal periodicity of rainfall in the Etosha National
Park and surrounding areas in northern Namibia. Madoqua 20 (1): 115-120.

EsTES, J.E. 2001. Elements, aids, techniques and methods of photographic/image interpretation. [Online]. In: Estes, J.E., K.C McGwIRE \& K.D. KLINE (eds.). Air Photo Intepretation and Photogrammetry. Volume 1. Available: "http:// umbc7.umbc.edu/ tbenja1/santabar/vol1/lec $2 / 21$ ecture.html" http://umbc7.umbc.edu/ tbenja1/ santabar/vol1/lec2/2lecture.html [accessed 2 July 2002].

Fahsi, A. 2001. Geometry of Aerial Photography. [Online]. In: Estes, J.E., K.C MCGwIRE \& K.D. KLINE (eds.). Air Photo Intepretation and Photogrammetry. Volume 1. Available: http:// umbc7.umbc.edu/ tbenja1/santabar/vol1/lec6/ 6lecture.html [accessed 2 July 2002].

Graetz, R.D. \& R.P. PeCh. 1987. Detecting and monitoring impacts of ecological importance in remote arid lands: a case study in southern Simpson Desert of South Australia. Journal of Arid Environments 12: 269-284.

Hudak, A.T. \& C.A. Wessman. 1998. Textural analysis of historical aerial photography to characterize woody plant encroachment in South African savanna. Remote Sensing of Environment 66: 317-330.

JoUBERT, S.C.J. 1983. A monitoring program for an extensive National Park. Pp. 201-213. In: OWEN-SMith, R.N. (ed.). Management of large mammals in African conservation areas. Pretoria: Haum.

KempF, J. \& D. Busche. 2002. Modelling environmental history in central Namibia since the Late Tertiary. Zeitschrift für Geo- und Umweltwissenschaften 146: 8-15.

LAMPREY, H.F. 1979: Structure and functioning of the semi-arid grazing land ecosystem of the Serengeti region (Tanzania). Pp 562-601. In: UNESCO/UNEP/FAO (eds.). Tropical grazing land ecosystems. Paris: UNESCO

LATHROP, R. 1999. Acquisition of aerial photographs [online]. Available: HYPERLINK "http://crssa. rutgers.edu/courses/airphoto/airphoto8/sld007. htm" (accessed 13 January 2003)

LiLLESAND, T.M \& R.W. KIEFER. 1994. Remote sensing and image interpretation. New York: John Wiley.

Lindaque, M. \& T.J. Archibald. 1991. Seasonal wetlands in Owambo and Etosha National Park. Madoqua 17 (2): 129-133.

Milton, S.J., W.R.J. Dean \& R.P. Ellis. 1998. Rangeland health assessment: a practical guide for ranches in arid Karoo shrublands. Journal of Arid Environment 39: 253-265

Moleele, N.M, S. Ringrose, W. Matheson \& C. VANDERPOST. 2001. More woody plants? The status of bush encroachment in Botswana's grazing areas. Journal of Arid Environment 64: 3-11. 
Rogan, J., J. Franklin \& D.A. Roberts. 2002. A comparison of methods for monitoring multitemporal vegetation change using Thematic Mapper imagery. Remote Sensing of Environment 80:143-156.

Sannier, C.A.D, J.C. Taylor, W.P. DU Plessis \& K. Campbell. 1995. Application of Remote Sensing and GIS for monitoring vegetation in Etosha National Park. Paper presented at: Remote sensing and GIS for Natural Resource Management RSS Workshop, 19 December 1995, Chatham, UK.

SAnNier, C.A.D, J.C. TAYlor \& W. DU Plessis. 2002. Real-time monitoring of vegetation bio- mass with NOAAA-AVHRR in Etosha National Park, Namibia, for fire risk assessment. International Journal of Remote Sensing 23(1): 71-89.

Scholes, R.J. \& B.H. Walker. 1993. An African savanna: synthesis of the Nylsvley study. Cambridge: Cambridge University Press.

Trodd, N.M. \& A.J. DougILl. 1998. Monitoring vegetation dynamics in semi-arid African rangelands. Applied Geography 18 (4): 315-330.

Walker, B.H \& I. NoY-MeIR. 1982. Aspects of the stability and resilience of savanna ecosystems. Pp. 577-590. In: HuntLey, B.J, \& B.H. WalKER, (eds.). Ecology of Tropical Savannas. Berlin: Springer-Verlag. 